\title{
Estimation of lung vital capacity before and after coronary artery bypass grafting surgery: a comparison of incentive spirometer and ventilometry
}

Areli Cunha Pinheiro', Michelli Christina Magalhães Novais', Mansueto Gomes Neto', Marcus Vinicius Herbst Rodrigues², Erenaldo de Souza Rodrigues Junior ${ }^{1,3,4}$, Roque Aras Junior ${ }^{3,4}$ and Vitor Oliveira Carvalho ${ }^{2^{*}}$

\begin{abstract}
Background: Measurement of vital capacity (VC) by spirometry is the most widely used technique for lung function evaluation, however, this form of assessment is costly and further investigation of other reliable methods at lower cost is necessary. Objective: To analyze the correlation between direct vital capacity measured with ventilometer and with incentive inspirometer in patients in pre and post cardiac surgery.

Methodology: Cross-sectional comparative study with patients undergoing cardiac surgery. Respiratory parameters were evaluated through the measurement of VC performed by ventilometer and inspirometer. To analyze data normality the Kolmogorov-Smirnov test was applied, for correlation the Pearson correlation coefficient was used and for comparison of variables in pre and post operative period Student's t test was adopted. We established a level of ignificance of 5\%. Data was presented as an average, standard deviation and relative frequency when needed. The significance level was set at 5\%.

Results: We studied 52 patients undergoing cardiac surgery, 20 patients in preoperative with VC-ventilometer: $32.95 \pm 11.4 \mathrm{ml} / \mathrm{kg}$ and VC-inspirometer: $28.9 \pm 11 \mathrm{ml} / \mathrm{Kg}, \mathrm{r}=0.7 \mathrm{p}<0.001$. In the post operatory, 32 patients were evaluated with VC-ventilometer: $28.27 \pm 12.48 \mathrm{ml} / \mathrm{kg}$ and VC-inspirometer: $26.98 \pm 11 \mathrm{ml} / \mathrm{Kg}, \mathrm{r}=0.95 \mathrm{p}<0.001$ Presenting a very high correlation between the evaluation forms studied.

Conclusion: There was a high correlation between DVC measures with ventilometer and incentive spirometer in pre and post CABG surgery. Despite this, arises the necessity of further studies to evaluate the repercussion of this method in lowering costs at hospitals.
\end{abstract}

Keywords: Assessment Vital Capacity, Cardiac surgery, physiotherapy, exercise

\section{Background}

Vital capacity (VC), defined as the maximum amount of air that can be exhaled after a maximum inhalation, is an indispensable measure for the diagnosis of pulmonary mechanical limitation as well as for adequation of pulmonary reexpansion therapy applied to patients after cardiac surgery. The normal value of the VC is from 65

\footnotetext{
* Correspondence: vitor.carvalho@usp.br

${ }^{2}$ Instituto do Coração do Hospital das Clínicas da Faculdade de Medicina da USP (InCor HC-FMUSP), São Paulo, Brazil

Full list of author information is available at the end of the article
}

to $75 \mathrm{ml} / \mathrm{kg}$, however, there may be variations regarding ethnicity, age, gender, height and weight [1-5].

The evaluation of pulmonary volumes and capacities is essential to characterize pulmonary mechanical limitation, especially in postoperative cardiac surgery patients $[6,7]$.

It has been described that $\mathrm{VC}$ lower than $25 \mathrm{ml} / \mathrm{Kg}$ can predispose atelectasis, hypoxemia and inefficient cough [6,7]. After cardiac surgery, the impairment of $\mathrm{VC}$ has a multifactorial meaning and the restrictive pattern can last for more than 116 days, predisposing 
atelectasis and post operatory complications [8-16]. In order to obtain pulmonary volumes and capacities, spirometry and ventilometry are the most used techniques in clinical practice, nevertheless, both methods are very costly and not always available in hospitals [3,5,17-20].

Due to its low cost, incentive spirometers are widely used in hospitals. They are used for treating and preventive purposes regarding pulmonary complications. This device works with visual stimulation to deep inspiration and is largely used by patients in post operatory periods of abdominal and thoracic surgery [21,22].

Due to the importance of accessing VC in patients who underwent cardiac surgery and considering the high cost of ventilometers and spirometries, arises the necessity of an inexpensive alternative method which can reflect in a reliable manner the $\mathrm{VC}$.

The aim of this study was to evaluate the incentive spirometers as a method of assessment $\mathrm{VC}$ in patients in pre and post coronary artery bypass grafting (CABG) surgery.

\section{Methods}

\section{Studied population}

This study was accomplished in a tertiary cardiac hospital with a group of patients in pre operatory and another group in the $5^{\text {th }}$ post operatory day of CABG surgery. Patients with smoking history, pulmonary diseases, extracorporeal circulation time higher than 150 minutes, intolerance and/or difficulties in understanding the technique were excluded.

This protocol was approved by the Ethical Committee of our institution. All patients provided informed consent prior to participation.

\section{Study design}

This cross-sectional prospective study was designed to study the direct vital capacity (DVC, $\mathrm{ml} / \mathrm{Kg}$ ) measured by ventilometer and Incentive spirometer before and after CABG surgery.

The execution order of DVC techniques measured with ventilometer and incentive spirometer were randomized through sealed envelopes. All participants were oriented regarding the methodology to be used in each measurement. In order to avoid bias in the results presented, data collection was made by only one researcher.

\section{DVC Measurement with ventilometer}

In order to measure DVC with ventilometer, the individuals were placed in a sitting position with thorax in a vertical way in approximately $90^{\circ}$. A ventilometer (Ferraris $^{\circledR}$ ) was used with a trachea in its shortest length, connected between the ventilometer and a hard flat mouthpiece. A nasal clip was used to avoid air escape by the nose. ${ }^{23}$ Then, the patients performed deep inspiration until total pulmonary capacity followed by continuous and slow expiration until residual volume. The technique was applied three times and the highest volume was considered.

\section{DVC Measurement with incentive inspirometer}

To assess DVC with an incentive spirometer, patients adopted the same positioning performed by the ventilometer. An inspirometer $\left(\mathrm{Coach}^{\circledR}\right)$ was used was used with a trachea in its shortest length, connected between the ventilometer and a hard flat mouthpiece. A nasal clip was used to avoid air escape by the nose. Then the patients performed deep slow expiration until residual volume, followed by continuous and deep inspiration until total pulmonary capacity, in which VC was measured through the numerical marking of the inspirometer. The technique was applied three times and the highest volume was considered.

\section{Statistical analysis}

Descriptive statistics was applied to analyze demographic and clinical data, continuous variable information were assessed as measures of central tendency and dispersion and expressed as averages and standard deviation. Dichotomous or categorical variables were evaluated with frequency measures and presented as percentages. To analyze data normality KolmogorovSmirnov test was applied. Since data was regularly distributed the correlation assessment between DVC measured with ventilometer and incentive inspirometer was based on Pearson correlation coefficient [23,25]. T-student test for independent samples was used to compare patients' variables in pre and post operatory periods. Bland-Altman plots with 95\% limits of agreements were also derived. The assessment occurred with use of software SPSS (Statistical Package for the Social Sciences) for Windows (version 14.0).

\section{Results}

Fifty two patients submitted to CABG surgery were evaluated, 20 patients in pre operatory (15 men) and 32 patients in post operatory ( 21 men) (table 1$)$. In table 2 averages and DVC standard deviation patterns accomplished through ventilometry and spirometry in pre and post operatory are described. The use of incentive spirometer was well tolerated and of easy comprehension by the patients.

Analyzing the obtained data, we can observe that DVC measures between ventilometer and inspirometer show high correlation in pre and post CABG surgery $(r=0.7$ and 0.95 respectively, $\mathrm{p}<0.01$ ) (Figures 1 and 2 ).

Figure 1 demonstrates correlation between DVC values in $\mathrm{ml} / \mathrm{Kg}$ with ventilometer and incentive 
Table 1 Demographic characteristics of patients in pre and post operatory cardiac surgery

\begin{tabular}{lcc}
\hline $\begin{array}{l}\text { VARIABLES } \\
\mathrm{N}=52\end{array}$ & $\begin{array}{c}\text { PRE OPERATORY } \\
\text { N (\%) AVERAGE } \pm \text { SD }\end{array}$ & $\begin{array}{c}\text { POST OPERATORY } \\
\text { N (\%) AVERAGE } \pm \text { SD }\end{array}$ \\
\hline Gender & & \\
Male & $15(75 \%)$ & $21(65 \%)$ \\
Female & $05(25 \%)$ & $11(35 \%)$ \\
Age & $49.7 \pm 15.13$ anos & $49.7 \pm 15.8$ anos \\
BMI & $24.8 \pm 3.3 \mathrm{~kg} / \mathrm{m}^{2}$ & $25.5 \pm 2.5 \mathrm{~kg} / \mathrm{m}^{2}$ \\
RF & $18.4 \pm 6 \mathrm{rpm}$ & $21.2 \pm 7.94 \mathrm{rpm}$ \\
TV & $717.7 \pm 315.9 \mathrm{ml}$ & $632.2 \pm 263.2 \mathrm{ml}$ \\
MV & $13.178 \pm 6.422 \mathrm{~L} / \mathrm{min}$ & $13.278 \pm 6.216 \mathrm{~L} / \mathrm{min}$ \\
\hline
\end{tabular}

BMI: Body mass index, RF: respiratory frequency, TV: tidal volume, MV: minute volume

inspirometer in patients before CABG surgery. DVC with ventilometer varied from 14.6 to $55.2 \mathrm{ml} / \mathrm{Kg}$ and DVC with incentive inspirometer varied from 9.2 to $52.7 \mathrm{ml} / \mathrm{Kg}$.

There was a correlation between DVC values in $\mathrm{ml} / \mathrm{Kg}$ with ventilometer and incentive inspirometer in patients after CABG surgery. DVC with ventilometer varied from 9 to $66.6 \mathrm{ml} / \mathrm{Kg}$ and DVC with incentive inspirometer varied from 7.7 to $52.8 \mathrm{ml} / \mathrm{Kg}$ (Figure 2).

In subsequent assessment a comparison of averages before and after CABG surgery was performed and it was observed that there were not significant disparities in DVC averages analysis (Table 2).

Bland Altman plots with $95 \%$ of agreement are shown in Figures 3 and 4. Cronbach's Alfa index was 0.82 to pre and 0.97 to post surgery.

\section{Discussion}

The main point of this research was the positive correlation between DVC measured with ventilometer and incentive spirometer. Furthermore, the use of incentive spirometer as DVC evaluation method was of easy execution and understanding by the patient.

Nowadays, studies have been carried out with the aim to standardize pulmonary function ways of assessment $[26,27]$. The investigation of evaluation methods for pulmonary function with high sensibility and specificity has

Table 2 Comparison with averages and Standard deviation variables: age, BMI, DVC through ventilometry and spirometry in pre and post operatory groups

\begin{tabular}{cccc}
\hline VARIABLES & $\begin{array}{c}\text { PRE OPERATORY } \\
\text { AVERAGE } \pm \text { SD }\end{array}$ & $\begin{array}{c}\text { POST OPERATORY } \\
\text { AVERAGE } \pm \text { SD }\end{array}$ & $p$ \\
\hline Age & $49.7 \pm 15.13$ years & $49.7 \pm 15.8$ years & 0.985 \\
BMI & $24.8 \pm 3.3 \mathrm{~kg} / \mathrm{m}^{2}$ & $25.5 \pm 2.5 \mathrm{~kg} / \mathrm{m}^{2}$ & 0.353 \\
DVCV & $32.95 \pm 11.4 \mathrm{ml} / \mathrm{Kg}$ & $28.27 \pm 12.48 \mathrm{ml} / \mathrm{Kg}$ & 0.304 \\
DVCl & $28.9 \pm 11 \mathrm{ml} / \mathrm{Kg}$ & $26.98 \pm 11 \mathrm{ml} / \mathrm{Kg}$ & 0.859
\end{tabular}

BMI: Body mass index, DVCV: direct vital capacity measured with ventilometer. DVCl: direct vital capacity measured with incentive inspirometer.

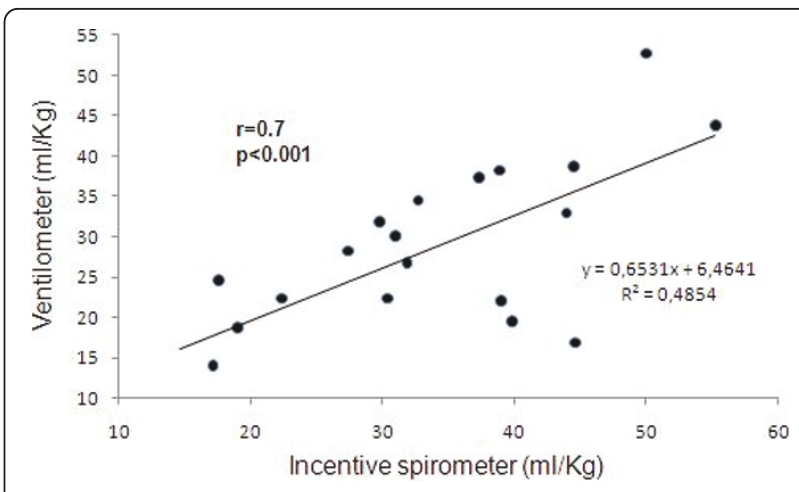

Figure 1 Correlation between DVC measured with ventilometer and incentive spirometer in pre operatory groups.

a great value for clinical practice, mainly when these techniques can be applied in a practical way, in bed and at low cost.

In literature there is an array of researches highlighting the importance of volumes and pulmonary capacities measurements. Chevrolet e Deleament [28] assure that VC is an important predictor of pulmonary function because it evaluates the mechanical ventilation necessity and success in ventilatory weaning. Suesada et al.[29] showed that VC was one of the variables with higher impairment after short length hospitalization. Gregorini et al.[23] reported that patients in post operatory of cardiac surgery showed decreased volumes and pulmonary capacities, therefore reducing the quantity of deep inspirations and cough effectiveness. The lessening of deep inspiration and cough has been proposed to predispose respiratory complications in which atelectasis is the most frequent, reaching approximately $64 \%$ of operated patients [23].

The ventilometer, as well as spirometry, is frequently used to evaluate $\mathrm{VC}$ in patients with respiratory dysfunctions, however, its cost and maintenance are also elevated $[18,19]$. This high cost motivates the use of alternative ways to access $\mathrm{VC}$ in clinical practice [30].

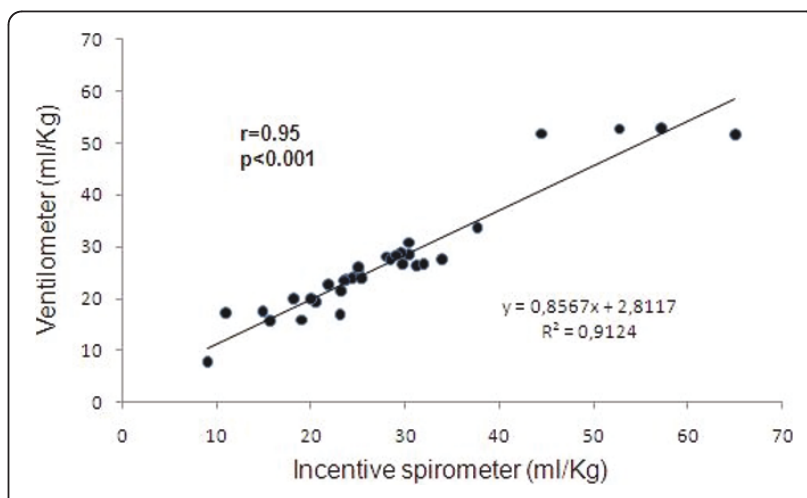

Figure 2 Correlation between DVC measured with ventilometer and incentive spirometer in post operatory groups 


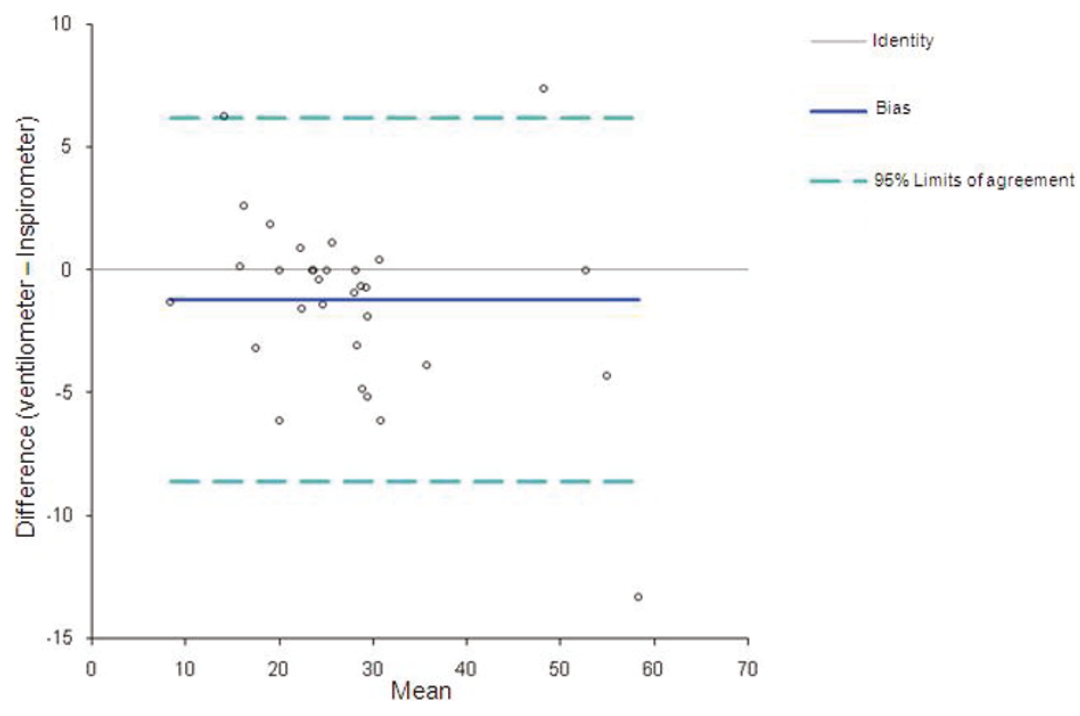

Figure 3 Bland \& Altman plots between Ventilometer and Spirometer pre cardiac surgery

The rationale of using an incentive spirometer to $\mathrm{VC}$ assessment is based on the fact that with ventilometer the patient could perform a deep inspiration until his total pulmonary capacity, followed by continuous and slow expiration until residual volume. With the incentive inspirometer, which operates through inspirations and volumetric registrations, the individual could perform the opposite from the ventilometer and the same air volume would be evaluated. This connection was highly evidenced in the results presented on this research, since the patients in pre and post operatory cardiac surgery showed homogeneous values of DVC measured by ventilometer and incentive spirometer (Figures 1 and 2).

The results of this present study could be used in further investigations in order to deepen the knowledge about the connection between DVC measured with ventilometer and incentive inspirometer.

\section{Conclusion}

There was a high correlation between DVC measures with ventilometer and incentive spirometer in pre and post CABG surgery. Despite this, arises the necessity of

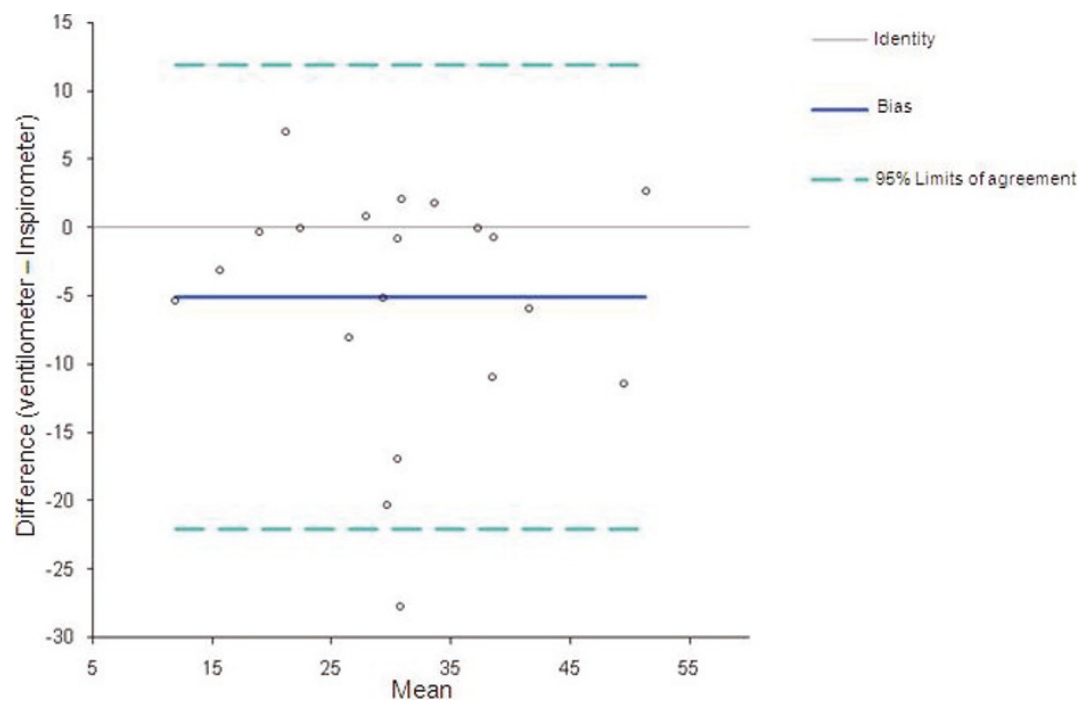

Figure 4 Bland \& Altman plots between Ventilometer and Spirometer post cardiac surgery. 
further studies to evaluate the repercussion of this method in lowering costs at hospitals.

\section{Acknowledgements}

The authors would like to thank the "Hospital Ana Nery - UFBA" for the opportunity of data collection.

\section{Author details}

${ }^{1}$ Faculdade Social, Salvador, Bahia, Brazil. ${ }^{2}$ Instituto do Coração do Hospital das Clínicas da Faculdade de Medicina da USP (InCor HC-FMUSP), São Paulo, Brazil. ${ }^{3}$ Hospital Ana Neri da Faculdade de Medicina da Universidade Federal da Bahia (HAN-UFBA), Salvador, Bahia, Brazil. ${ }^{4}$ Faculdade de Medicina da Universidade Federal da Bahia, Salvador, Bahia, Brazil.

\section{Authors' contributions}

VOC and ESRJ were involved with study design, ACP collected the data, MGN and VOC performed the data analysis, MVHR, RAJ and MCMN were involved with data discussion. All authors have read and approved the manuscript.

\section{Competing interests}

The authors declare that they have no competing interests.

Received: 3 January 2011 Accepted: 12 May 2011

Published: 12 May 2011

\section{References}

1. Neder JA, Andreoli S, Castelo-Filho A: Reference values for lung function tests. I.Static volumes. Braz J Med Biol Res 1999, 32:703-17.

2. Eaton T, Withy S, Garrett JE: Spirometry in primary care practice. The importance of quality assurance and the impact of spirometry workshops. Chest 1999, 116:416-23.

3. Scalan CL, Wilkins RK, Stoller : Fundamentos da terapia respiratória de Egan. 7a edição. Editora Manole Ltda. São Paulo 2000.

4. Rodrigues JC, Cardier JMA, Dussamra MHCF, Nakaie CMA, Almeida MB, Silva Filho LVF, Adde FV: Provas de função pulmonar em crianças e adolescentes. J Pneumol 2002, 28:207-221

5. Mallozi MC: Valores de referencia para espirometria em crianças e adolescentes, calculados a partir de uma amostra da cidade de São Paulo. (Tese). São Paulo: Universidade Federal de São Paulo - Escola Paulista de Medicina 1995.

6. Forgiarini LA Jr, Rubleski A, Douglas G, Tieppo J, Vercelino R, Dal Bosco A, Monteiro MB, Dias AS: Evaluation of respiratory muscle strength and pulmonary function in heart failure patients. Ara Bras Cardiol 2007, 89:36-41.

7. Newton-John H: Prevention of pulmonary complications in severe Guillain-Barré syndrome by early assisted ventilation. Med J Aust 1985, 142:444-5

8. Yavagal DR, Mayer SA: Respiratory complications of rapidly progressive neuromuscular syndromes: Guillain-Barré syndrome and myasthenia gravis. Semin Respir Crit Care Med 2002, 23:221-9.

9. Vargas FS, Terra-Filho M, Hueb W, Teixeira RL, Cukier A, Light RW: Pulmonary function after coronary artery bypass surgery. Respir Med 1997, 91:629-33.

10. Guizilini S, Faresin SM, Carvalho ACC, Jaramillo Jl, Alves FA, et al: Effects of the pleural drain site on the pulmonary function after coronary artery bypass grafting. Rev Bras Cir Cardiovasc 2004, 19:47-54.

11. Taggart DP, El-Fiky M, Carter R, Bowman A, Wheatley DJ: Respiratory dysfunction after uncomplicated cardiopulmonary bypass. Ann Thorac Surg 1993, 56:1123-8.

12. Renault JA, Val RC, Rossetti MB: Fisioterapia respiratória na disfunção pulmonar pós-cirurgia cardíaca. Rev Bras Cir Cardiovasc 2008, 23:562-9.

13. Lichtenberg A, Hagl C, Harrier W, Klima U, Haverich A: Effects of minimal invasive coronary artery bypass on pulmonary function and postoperative pain. Ann Thorac Surg 2000, 70:461-5.

14. Giacomazzi CM, Lagni VB, Monteiro MB: Does the pain disturb the respiratory function after open heart surgery? Rev Bras Cir Cardiovasc 2009, 24:490-496.
15. Dias CM, Plácido TR, Ferreira MFB, Guimarães FS, Menezes SLS: Incentive spirometry and breath stacking: effects on the inspiratory capacity of individuals submitted to abdominal surgery. Rev Bras Fisioter 2008 12:94-9.

16. Ropper AH: Critical care of Guillain-Barre syndrome. In Ropper AH, ed Neurological and neurosurgical intensive care. New York, Raven Press; 1993, p371.

17. Barreto SSM: Volumes pulmonares. J Pneumol 2002, 28:83-94

18. Boskabady MH, Keshmiri M, Banihashemi B, Anvary K: Lung function volues in healthy non-smoking urban adults in iran respiration. JPMA 2002, 69(4):320-6.

19. Memon MA, Sandila MP, Ahmed ST: Spirometry reference values in healltlly, now smoking, urban pakistani population. J Pak Med Assoc 2007, 57:193-5.

20. Bosoglu OK, Atasever A, Bakakoglu F: The efficacy of incentive spirometry in patients with COPD. Respirology 2005, 10:349-353.

21. Agostini P, Calvert R, Subramanian H, Naidu B: Is incentive spirometry effective following thoracic surgery? Interactive Cardiovascular and Thoracic Surgery 2008, 7:297-300.

22. Rouquayrol MZ, Almeida Filho N: Epidemiologia a Saúde. 6 ed. Editora Medsi. São Paulo 2003.

23. Aquino LM, Branco JNR, Bernardelli GF: Short-duration transcutaneous electrical nerve stimulation in the postoperative period of cardiac surgery. Ara Bras Cardiol 2010, 94:325-31.

24. Domholdt E: Physical therapy research; Principles and Applications. WB Saunders Company, USA; 22000

25. Lopes AA: Medicina baseada em evidencias: a arte de aplicar o conhecimento cientifico na prática clínica. Rev Assoc Med Bras 2000, 46:285-288.

26. America Thoracic Society/European Respiratory Society. ATS/ERS statement on respiratory muscle testing. Am J Respir Crit Care Med 2002, 166:518-624

27. Sociedade Brasileira de Pneumologia e Tisiologia. Diretrizes para testes de função pulmonar. J Pneumol 2002, 28:S1-S238.

28. Chevrolet JC, Deleamont P: Repeated vital capacity measurements as predictive parameters for mechanical ventilation need and weaning success in Guillain-Barré syndrome. Am Rev Respir Dis 1991, 144:814-8.

29. Suesada MM, Martins MA, Carvalho CR: Effect of short-term Hospitalization on functional capacity in patients not restricted to Bed. Am J Phys Med Rehadil 2007, 86:455-62.

30. Ropper AH: Acute inflammatory post infectious polyneuropathy. In Neurological and Neurosurgical Intensive Care. Edited by: Roppere AH, Kennedy SF. Gaitherburg, MD Aspen Publications; 1991:

doi:10.1186/1749-8090-6-70

Cite this article as: Pinheiro et al: Estimation of lung vital capacity before and after coronary artery bypass grafting surgery: a comparison of incentive spirometer and ventilometry. Journal of Cardiothoracic Surgery 2011 6:70.

\section{Submit your next manuscript to BioMed Central and take full advantage of:}

- Convenient online submission

- Thorough peer review

- No space constraints or color figure charges

- Immediate publication on acceptance

- Inclusion in PubMed, CAS, Scopus and Google Scholar

- Research which is freely available for redistribution 